\title{
Seismic Response Control of Elevated Water Tank using Base Isolation
}

\author{
Sanket Nimbekar ${ }^{1}$, Dr. K. R. Dabhekar ${ }^{2}$, Prof. S. S. Solanke², Dr Isha P Khedikar ${ }^{4}$, Er. Tushar H. Sonawane \\ ${ }^{1}$ Research Scholar, Civil Engineering Department, G H Raisoni College of Engineering, Nagpur, India \\ ${ }^{2}$ Assistant Professor, Civil Engineering Department, G H Raisoni College of Engineering, Nagpur, India \\ ${ }^{3}$ Assistant Professor, Civil Engineering Department, G H Raisoni College of Engineering, Nagpur, India \\ ${ }^{4}$ Assistant Professor, Civil Engineering Department, G H Raisoni College of Engineering, Nagpur, India \\ ${ }^{5}$ Director, Tushar Sonawane and Associates-Consulting Civil \& Structural Engineers, Nashik, India
}

\section{Article Info \\ Volume 8 Issue 2 \\ Page Number: 351-354}

Publication Issue :

March-April-2021

\section{Article History}

Accepted : 15 April 2021

Published : 24 April 2021

\section{ABSTRACT}

A water tank is a raised design developed at a stature productive to give crisis stockpiling to fire assurance and to compress a water supply framework for the dissemination of consumable water. The raised water tank can be separated into two kinds in light of size, shape, materials and motivation behind utilize Elevated water stockpiling tank and Ground upheld tank. [4, 8] Among different design raised storagereservoir are the constructions which need to stay useful after serious quake occasion for help activity and to control fire breakouts and so forth consequently, the seismic conduct of raised tank ought to be known and perceived, and they ought to be plan to be tremor safe. $[1,17]$ Water is human essential need for everyday life. Raised water tank comprises of a enormous water mass at the highest point of thin organizing which are most significant thought for the disappointment of the tank during seismic tremor, raised water tanks are basic and key constructions and harm of these structures during quake may jeopardized drinking water supply. Enormous quantities of papers have been distributed till date identified with seismic reaction of raised water tank. Specialists utilize various sorts of model and scientific and test strategies to discover the seismic reaction of these constructions. Such examinations are being use to give rules and proper techniques to guarantee wellbeing of raised water tanks quite far in the occasion earthquake.[7] Elevation of the repository is given through organizing. Arranging by and large has underlying framework packing of segment and level supports which sends the heap to establishment. Water tank conduct on organizing is significant and should be assessed. In this examination, assessed seismic execution of raised water stockpiling tank by putting base confinement framework utilizing SAP2000. [19] The investigation of raised storage is performed on incautious mode and convective mode utilizing the code IS 1893(part2) and furthermore, we 
considered the powers in both tank full conditions and tank void condition. From this examination the powers dealing with raised water tank because of seismic powers are determined for zone IV. [18].

Keywords : Elevated Water Tank, SAP 2000, Response spectrum analysis, Base shear, Base Moment, Displacement, Time period, hydrostatic forces staging pattern.

\section{INTRODUCTION}

The Indian subcontinent has a background marked by stripping seismic tremors. The significant explanation behind the recurrence and force of the quakes is that Indian plate is crashing into Asia. In numerous nations, numerous earthquakes have happened in a steady progression for 10 years. To shield structures from critical harm and reaction decrease of constructions under such extreme tremors has become a significant theme in underlying designing. [3]

\section{Seismic Analysis}

Seismic Analysis is a primary examination and is the computation of the reaction of a structure construction to tremor. It is important for the cycle of underlying harm, quake designing or primary appraisal and retrofit (primary designing) in districts where seismic tremors are common. $[1,4]$

A tank can possibly 'wave' to and fro during a seismic tremor (or even an extreme breeze storm). This is known as the 'principal mode' and is the most minimal recurrence of tank reaction. Most tanks, be that as it may, have higher methods of reaction, which are extraordinarily enacted during quakes. $\quad[7$, 10]

Seismic analysis is needed for completing the foundational layout, underlying evaluation and retrofitting of the designs in the locales where tremors are predominant. Different seismic information is important to do the seismic investigation of the constructions. This information are available into two different ways viz. in deterministic structure or in probabilistic structure. Information in deterministic structure is utilized for plan of constructions and so forth though information in probabilistic structure are utilized for investigation of design exposed to arbitrary vibration, seismic danger examination and harm evaluation of designs under specific quake ground movement. Major seismic information incorporates ground quickening/relocation information/speed, size of quake, top ground boundaries, length and so on $[1,14]$

\section{Response spectrum analysis}

As per study $[9,19]$ Response-spectrum analysis (RSA) is a direct unique factual examination technique which quantifies the commitment from every characteristic method of vibration to show the possible greatest seismic reaction of a basically flexible design. As a component of primary period for a given time history and level of damping reaction range examination gives understanding into dynamic conduct by estimating pseudo-ghastly speeding up, speed, or relocation. It is common-sense to envelope reaction spectra a particularly smooth bend addresses the stature reaction for each acknowledgment of primary period. Reaction range examination is useful for plan dynamic since it relates primary sort determination to dynamic execution. Designs of longer period experience more noteworthy uprooting, though those of more limited period experience more prominent speeding up. During primer plan and reaction range examination underlying execution 
targets ought to be considered.

\section{Damping}

Damping in the convective mode for a wide range of tanks and for a wide range of fluids will be taken as $0.5 \%$ of the basic. Damping in the indiscreet mode will be taken as $2 \%$ of the basic for steel tanks and $5 \%$ of the basic for cement or workmanship tanks. [5]

\section{Isolators and type of isolators.}

Different examinations $[1,5]$ have demonstrated that viability of seismic segregation increments with the expansion of bearing adaptability and damping. With essentially less computational endeavours the proposed rough strategies precisely anticipate the pinnacle reaction of the confined raised steel tank. Assessment of greatest hydrodynamic pressing factor coming about because of the indiscreet and convective modes demonstrated that the most extreme pressing factor happens at the lower levels of water free surface. Most extreme pressing factor happens at the lower part of full tank, since indiscreet pressing factor is prevailing in these levels. For inflexible sort tower structure the detachment framework is more viable. Mathematical and scientific estimation approaches are looked at on the case of regular tank calculation, considered the significant communication impacts. The viability of segregation frameworks for tanks increments with the ascent of the malleability of the sliding frameworks.

\section{Working of Isolators}

As per study $[5,10]$ during an earthquake Seismic base confinement of round and hollow, groundupheld, fluid stockpiling, steel tanks has been proposed by separating the mass of the tank from the base plate and supporting it on a ring of on a level plane adaptable orientation and the base plate is upheld straightforwardly on the ground. The hole between the base plate and the divider is shut with an adaptable film which permits the divider to move openly the level way. It is seen that segregation decreases drastically then estimations of hydrodynamic toppling minutes, base shears, and the pivotal compressive anxieties in the tank without a critical expansion in free-surface sloshing. During solid ground shaking the orientation in thin tanks experience a net pliable power, since the dead weight upheld by the heading is little contrasted with the complete fluid weight. The expense saving in the even limitation, base dock, establishment and the tank material is probably going to balance altogether the extra expense of the detachment heading, adaptable layer, and the base stiffener.

\section{Structural Analysis Programs}

Many studies [7-15] show that the manual procedure of seismic analysis for any structure with isolators will prove to be lengthy and time consuming. Mainly used structural analysis programs are ETABS, SAP2000, and STAAD Pro. The procedure of analysing structure with the help of such software can be time saver. While modelling and analysing the structure, specific construction code for the analysis purpose is available in software. The software analysis procedure includes modelling of the model, assigning section and material properties, assigning load patterns and load cases. Selection of code required for analysis purpose. The analysis type includes static, dynamic, linear, non-linear, response spectrum analysis. Depending on the load cases the values of maximum base shear, absolute acceleration, absolute displacement, storey drift from the analysis obtained can be varying for different storeys. The various results obtained can be compared and then the design or data for isolation system to be used can be determined. There can be difficulty in assigning a particular analysis type for a particular damping system, to obtain the results. In the study [10] particular type of analysis to be adopted for the particular type of isolation system, which will be used is found out. 


\section{SAP 2000.}

SAP2000 is an underlying investigation and plan programming delivered by Computer and Structures Incorporated a primary and quake designing organization. SAP2000 is a universally useful limited component program which plays out the dynamic or static nonlinear or straight investigation of underlying frameworks. It is a likewise a ground-breaking configuration device to configuration structures following AASHTO details, AISC and ACI building codes. SAP2000 is a full highlighted program that can be utilized for the most perplexing activities or the easiest issues. It includes amazing graphical UI that is unequaled regarding usability and efficiency. [19]

\section{CONCLUSION}

The conclusions from the above studies are:

a) It is concluded that by the use of various techniques such as isolators, dampers, shear wall and bracing system seismic forces that causes base shear and overturning of water tank can be reduced.

b) Seismic response of water tank is different for different a staging pattern which is used to minimize displacement.

c) Thus, in this study we are going to use base isolators to check the performance of tank staging during earthquake vibrations which will be compared with non-isolated tank.

\section{REFERENCES}

[1]. Motwani, Mrs Meet. "Vibration Control of Elevated Water Tank Using Different Seismic Control Techniques-A Review."

[2]. Dr..Pajgade P.S, Mr. Waghmare P. B., Dr. Kanhe N.M. "Seismic Response of Isolated
Liquid Storage Tanks with Elastomeric Bearings."

[3]. Dr. Potnis S.C., Ms. Sutar P. S. "Earthquake response of the liquid storage tank with various isolation systems."

[4]. Mr. Birtharia A., Mr. Jain S. K. "Seismic response of elevated water tank."

[5]. Mr. Deshmukh G. P., Mr. Patekar S. "Analysis of elevated water structure using staging system."

[6]. Dr. P.S.Pajgade, Pravin B. Waghmare and Dr. N.M.Kanhe, "Seismic Response of Isolated Liquid Storage Tanks with Elastomeric Bearings (2013)."

[7]. Dr. S.C.Potnis, Poonam S. Sutar, "Earthquake response of the liquid storage tank with various isolation systems(2013)."

[8]. Mr. Birtharia A., Mr. Jain S. K. "Seismic response of elevated water tanks: an overview."

[9]. Neha N. Walde, Sakshi Manchalwar, Amey Khedikar, "Seismic Analysis of Water Tank Considering Effect on Time Period."

[10]. G. P. Deshmukh, Ankush S. Patekar, "Analysis of elevated water storage Structure using Different staging system (2015)."

[11]. Mor Vyankatesh K., More Varsha T. "Comparative study on dynamic analysis of elevated water tank frame staging and concrete shaft supported."

[12]. Ankit Agarwal, "Department of Structure Engineering, Faculty of Technology UTU Dehradun, India ,Pooja Semwal."

[13]. Asari Falguni P, Prof. M.G.Vanza, "Structural Control System For Elevated Water Tank."

[14]. Mayank Gopal Manwani, Deepa P.Telang, "Review on seismic analysis of elevated water tank with variations of $\mathrm{H} / \mathrm{D}$ ratio and container shape."

[15]. Manish N. Gandhi, Ancy Rajan, "Earthquake resistant analysis of circular elevated tank with different bracings in staging." 
[16]. M.K. Shrimali, R.S. Jangid: "Seismic response of liquid storage tanks isolated by sliding bearings."

[17]. M.B. Jadhav and R.S. Jangid: "Response of baseisolated liquid storage tanks."

[18]. P.L.N.Saroja: "Comparative Study Of Analysis of Elevated Water Tank Due To Earthquake From Different Zones Of Earthquake."

[19]. Tejaswini M.S., Sridhar. R-Comparative: "Study on Behaviour of Elevated Water Tank with Soil Structure Interaction Subjected to Seismic Load Using Sap 2000."

[20]. Dr. R.B. Khadiranaikar, Abbas Ali Dhundasi: "Equition For Estimation of Fundamental Time Period for Elevated Water Tank."

[21]. Chirag N.Patel and H.S. Patel: "Supporting System For Renforced Concrete Elevated Water Tank: A State- Of-The Art Liturature Review."

[22]. Suyash Nerkar, Chittaranjan Nayak: "Seismic Behavior Of Elevated Storage reservior By Finite Element Method."

[23]. Atsushi MORI, Ryoichi Fujita, Kiyoshi Yasug, Ryoji Iso, Yuichi HAYASHI And Kenji NIWA: "A Study on a Seismic Verification and Retrofit Method for An Elevated Water Tank Against Strong Earthquakes.

\section{Cite this article as :}

Sanket Nimbekar, Dr. K. R. Dabhekar, Prof. S. S. Solanke, Dr. Isha $\mathrm{P}$ Khedikar, Er. Tushar H. Sonawane, "Seismic Response Control of Elevated Water Tank using Base Isolation", International Journal of Scientific Research in Science, Engineering and Technology (IJSRSET), Online ISSN : 2394-4099, Print ISSN : 2395-1990, Volume 8 Issue 2, pp. 351-354, March-April 2021. Available at doi : https://doi.org/10.32628/IJSRSET218285 Journal URL : https://ijsrset.com/IJSRSET218285 